\title{
Overview and Genesis Analysis of the Intense Tropical Cyclone IDAI in the South-West Indian Ocean
}

\author{
Saisai Liu \\ Unit 31010 of People's Liberation \\ Army \\ Beijing, China \\ liusaisai_2014@sina.com
}

\author{
Dandan $\mathrm{Yu}$ \\ Unit 31010 of People's Liberation \\ Army \\ Beijing, China
}

Xudong Peng

Unit 31010 of People's Liberation Army

Beijing, China

\section{南印度洋强热带气旋
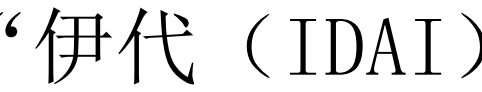 \\ 大分杆}

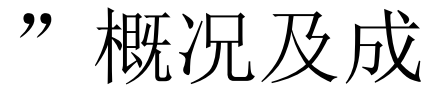

Yija $\mathrm{Hu}$

College of Meteorology and

Oceanography

National University of Defense

Technology

Nanjing, China
刘赛赛

解放军 31010 部队

北京 100081 , 中国

liusaisai_2014@sina.com
余丹丹

解放军 31010 部队

北京 100081，中国

彭旭东

解放军 31010 部队

北京 100081 , 中国

\begin{abstract}
In this paper, the NCEP reanalysis data and the sea surface temperature data are used to diagnose the development process of the intense tropical cyclone "IDAI" generated in the South- West Indian Ocean. The results show that the presence of the high pressure ridge in the northeast and the weak high pressure in the south makes "IDAI" moving slowly or even stagnantly. According to the intensity, the development of "IDAI" can be divided into three processes: the rapid strengthening process, the weakening maintenance process and the secondary strengthening process. Then it eventually developed into an intense tropical cyclone. The high sea temperature, the relatively small vertical wind shear and the favorable high-level divergence conditions are benifit environmental conditions for its rapid strengthening; during its development process, the external water vapor transport is weak, the water vapor and heat mainly come from the ocean; the eye wall replacement process causes the second strengthening of its intensity. Finally it landed in Mozambique with an intensity of intense tropical cyclone.
\end{abstract}

Keyword-South-West Indian Ocean, Tropical cyclone, Genesis analysis

摘要一本文利用 NCEP 再分析资料、海温资料等对西南印度洋 生成的强热带气旋 “伊代”（Idai）的发展过程进行了诊断 分析, 结果表明: 其东北侧的高压脊及西南侧弱高压的存在
使得 “伊代” 移动缓慢甚至停滞不前; “伊代” 经历了快速 加强阶段、减弱维持阶段以及二次加强阶段, 最终发展成为 强热带气旋, 较高的海温、相对较小的垂直风切变以及良好 的高层辐散条件是其发展加强的有利环境条件, 使其强度能 够迅速发展; 其发展过程中外部水汽输送较弱, 水汽和热量 主要来自海洋; 眼墙置换过程促使其强度二次爆发, 最终以 强热带气旋级登陆莫桑比克。

\section{关键词一西南印度洋, 热带气旋, 成因分析}

\section{I. 引言}

热带气旋（TC）经常给热带和亚热带海岸带来大雨 和强风, 是西南印度洋 (SWIO) 的主要威胁。事实 上, 近几十年来, 很多风暴给毛里求斯, 留尼汪岛, 马 达加斯加, 莫桑比克和其他国家造成了不同程度的破 坏。在这个地区, 热带气旋活动几乎与北大西洋盆地一 样强烈, 但受到的关注却少得多。目前国内很少有针对 西南印度洋热带气旋的相关研究, 仅国外一些学者对其 气候特点进行了一些分析 ${ }^{[1-5]}$ 。研究表明, 全球热带风暴 ( TS ) 和热带气旋 ( TC, 风力 $\geq 12$ 级) 的年平均数分别 为 84 和 45 。 SWIO 占全球年度活动的 $10-12 \%$, 平均 10.5 个 $\mathrm{TS}$, 其中 4.5 个成为 $\mathrm{TC}^{[6-7]}$ 。

资助项目 国家自然科学基金（41675077）

Found by National Natural Science Foundation of China (Grants 411675077) 
SWIO 热带气旋活动主要位于马达加斯加东部海域 ( $\left.10-20^{\circ} \mathrm{S}, 55-70^{\circ} \mathrm{E}\right)$, 其次是靠近的查戈斯群岛东部 $\left(15^{\circ} \mathrm{S}, 85^{\circ} \mathrm{E}\right)$ 和莫桑比克海峡附近 $\left(20^{\circ} \mathrm{S}, 40^{\circ} \mathrm{E}\right)$ [1]。虽然不像东北太平洋和西北太平洋那样强烈, 但 SWIO 的最大 TC 频率与孟加拉湾（其范围要小得 多）、澳大利亚西北部和东北部的相对相似。

强热带气旋“伊代（Idai）”是有记录以来影响非洲 和南半球的最严重的热带气旋之一。这个长生命史的风 暴在莫桑比克, 津巴布韦和马拉维造成严重洪灾, 产生 灾难性的破坏, 1000 多人死亡, 数千人失踪。一般来 说, 热带气旋靠近陆地时由于摩擦力增大, 强度一般很 难继续增强, 但是“伊代”从靠近陆地的地方生成, 以低 压强度登陆后又入海, 能够在海峡内部快速发展并加强 为强气旋风暴，实属罕见。

随着经济全球化的发展、“一带一路”的开展, 越来 越多企业选择在海外建设工厂, 越来越多华人在海外工 作或旅行, 防范自然灾害尤为重要。另外, 我国对非洲 一些国家的援建、开展海外人道主义救援等活动都需要 我们对当地的气候有所了解。

本文以“伊代”为研究对象, 分析其发展过程及成 因, 为今后在实际业务中南印度洋热带气旋的路径和强 度预报工作提供一些参考, 为开展印度洋热带气旋评估 及风险区划打下基础以及为我国一带一路沿海港口和海 外军事基地的建设提供辅助决策建议。

\section{II. 资料与方法}

\section{A. 资料}

本文诊断所用的资料主要来自美国 NCEP FNL $1^{\circ} \times$ $1^{\circ}$ 逐 6 小时再分析资料和 NOAA $0.5^{\circ} \times 0.5^{\circ}$ 日平均海
温资料, 热带气旋路径资料来源于法国气象局网站

(http://www.meteo.fr/temps/domtom/La_Reunion/webcmrs 9.0/anglais/index.html）。

\section{B. 西南印度洋热带气旋等级划分}

全球各气象机构对热带气旋的划分标准有所不同, 且各地区选择的热带气旋风速计算存在差异。不同于我 国使用的 “2 分钟平均风速” 作为持续风速, 西南印度 洋海域的热带气旋使用世界气象组织建议的 “ 10 分钟平 均风速” 作为持续风速 ${ }^{[6]}$ 。表 1 给出了西南印度洋热带 气旋划分等级及与西北太平洋划分的对比。

\section{C. 诊断量计算方法}

\section{(a) 高层平均散度}

多层平均定义为:

$$
U_{m}=\frac{\int U d p}{\int d p}
$$

利用上述方法，先对 $300 \sim 150 \mathrm{hPa}$ 的 $(U, V)$ 场 分别求取高层平均 $\left(U_{m}, V_{m}\right)$, 后利用中央差求取散度 $\operatorname{Div}\left(U_{m}, V_{m}\right)$ 。

（b）垂直风切变

利用求多层平均的方法 (公式 (1) ), 先对 300$150 \mathrm{hPa}$ 的风场 $\left(U_{1}, V_{1}\right)$ 分别求取高层平均 $\left(U_{m 1}, V_{m 1}\right)$, 再 对 925-700hPa 的风场 $\left(U_{2}, V_{2}\right)$ 分别求取高层平均

$\left(U_{m 2}, V_{m 2}\right)$, 得到垂直风切变 $U^{\prime}=U_{m 1}-U_{m 2}$, $V^{\prime}=V_{m 1}-V_{m 2} \circ$

表 1 西南印度洋热带气旋等级划分

\begin{tabular}{|c|c|c|c|}
\hline $\begin{array}{c}\text { 西南印度洋热带气旋 } \\
\text { 等级 }\end{array}$ & 英文全称 & $\begin{array}{c}\text { 中心附近最大 } \\
\text { 平均风速 } \\
\text { (knots) }\end{array}$ & $\begin{array}{l}\text { 中心附近最大 } \\
\text { 风力 (级) }\end{array}$ \\
\hline 热带低压 & Tropical Depression & $28 \sim 33$ & 7 \\
\hline 中等热带风暴 & Moderate Tropical Storm & $34 \sim 47$ & $8 \sim 9$ \\
\hline 强热带风暴 & Severe Tropical Storm & $48 \sim 63$ & $10 \sim 11$ \\
\hline 热带气旋 & Tropical Cyclone & $64 \sim 89$ & $12 \sim 14$ \\
\hline 强热带气旋 & Intense Tropical Cyclone & $90 \sim 115$ & $15 \sim 17$ \\
\hline 非常强的热带气旋 & Very Intense Tropical Cyclone & 115 & $>17$ \\
\hline
\end{tabular}

III. “伊代” 发展概况

“伊代” 为西南印度洋 2018一-2019 热带气旋季的第 11 个风暴（有命名的第 10 个），起源于 3 月 4 日在莫 桑比克东海岸形成的热带低压 (法国气象局留尼汪岛办 事处将其标记为 “热带低压 11 ” ), 并于当日在莫桑比 克登陆（图 1a）。在陆地上活动五天后，3 月9 日，热 带低压重新出现在莫桑比克海峡, 并在第二天（10日 00 时）加强为中等热带风暴 “伊代” 。随后其快速加强, 在 3 月 11 日达到强热带气旋初始峰值强度, 持续风速为 $175 \mathrm{~km} / \mathrm{h}$ 。随后 “伊代” 开始减弱, 降至热带气旋强 度, 维持一天左右之后, 3 月 14 日，“伊代” 达到其最 高强度, 最大持续风速为 $194 \mathrm{~km} / \mathrm{h}(53.8 \mathrm{~m} / \mathrm{s}$, 相当于我 国的超强台风），中心最低压力为 $940 \mathrm{hPa}$ 。 3 月 15 日，
“伊代” 以强热带气旋级在莫桑比克贝拉附近登陆, 随 后在 3 月 16 日逐渐减弱停编。但 “伊代” 的残余环流在 内陆继续移动, 最终于 3 月 21 日在莫桑比克海峡消散。 


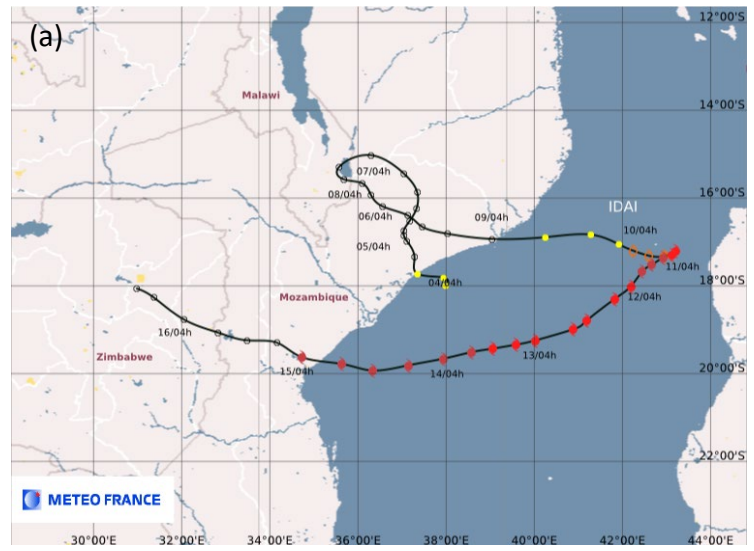

(b)

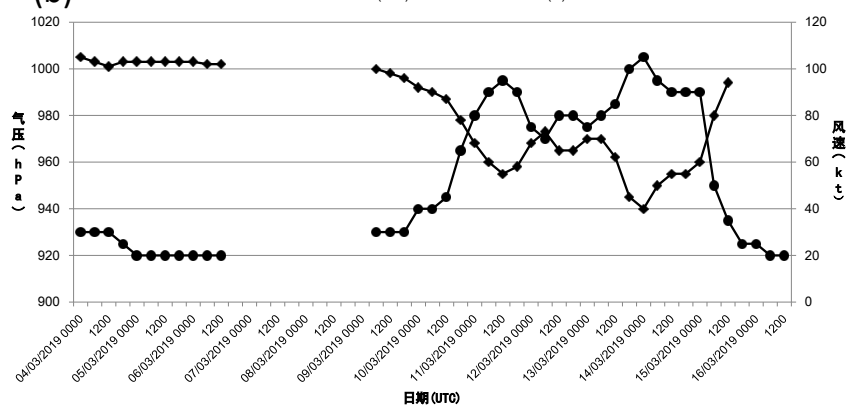

图 13月 4日 00 时至 3月 16 日 12 时(a) “伊代” 路径（图 中时次为法国时) 和(b)强度变化

从强度变化（图 1b）来看，“伊代” 的发展主要经 历了三个阶段：快速增强阶段（3 月 9 日 18 时一 11 日 12 时），减弱稳定阶段（3月 11 日 18 时一 13 日 00 时） 和二次加强阶段（3月 13 日 06 时一 14 日 00 时）。
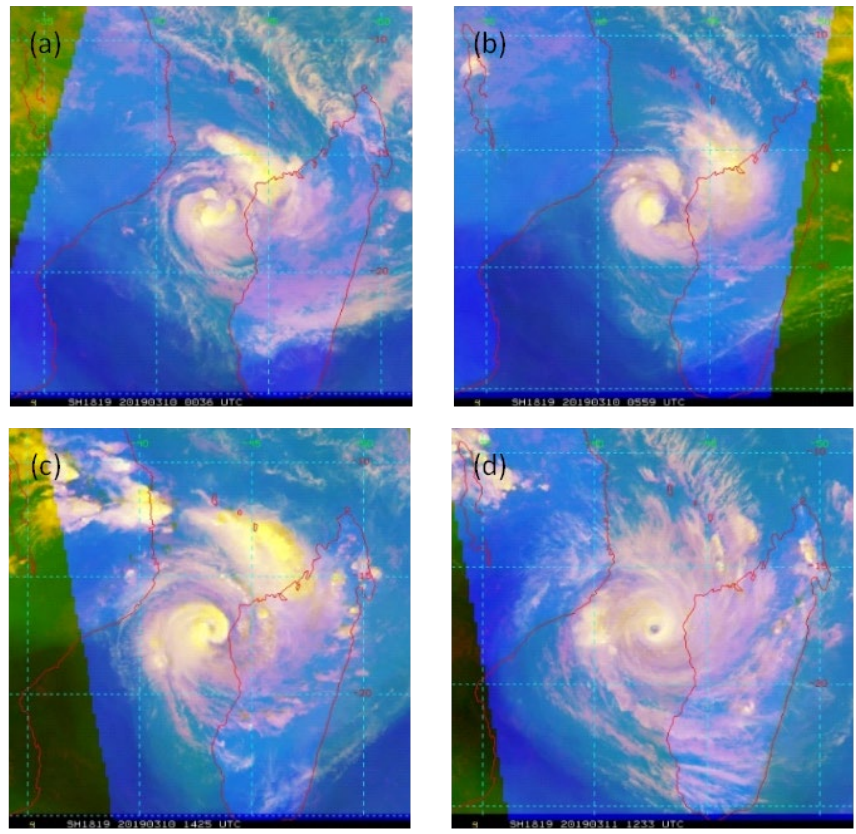
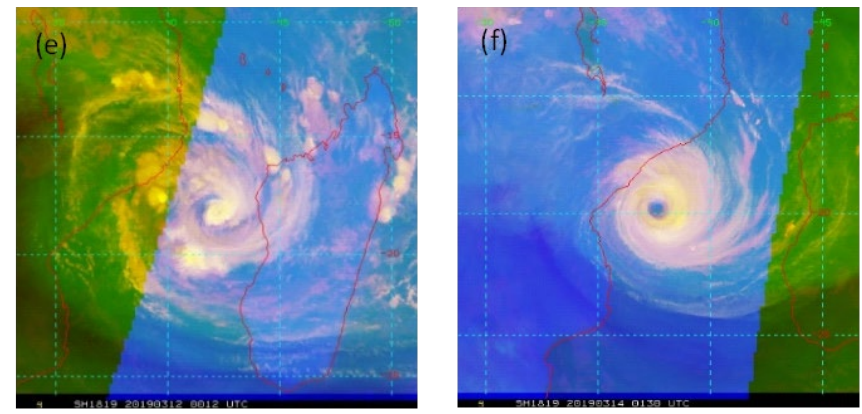

图 23 月 10 日 00 时 (a)、06 时 (b)、14 时 (c)、 11 日 12 时 (d)、 12 日 00 时 (e)、 14 日 01 时 (f) 红外卫 星云图

从卫星云图来看, 3 月 10 日 00 时左右（图 2a）, 气旋主体附近已经出现对流爆发, 随后对流继续发展, 气旋强度也快速加强, 到 10 日 14 时左右 (图 2c) 出现 明显台风眼, 11 日 12 时 (图 2d) 强度达到一个极值, 此时台风眼清晰可见, 螺旋云带结构明显; 到 12 日 00 时（图 2e）, 台风眼不再清晰, 此时气旋进入眼墙调整 阶段, 强度减弱, 随后其眼墙完成重组, 强度再次加 强, 并在 14 日 00 时达到第二个极值, 此时风眼明显比 第一个阶段大很多, 随后气旋强度也有所减弱。

本文将从海温、垂直风切变、水汽条件和高层辐散 的角度分析 “伊代” 发展加强的成因。

\section{IV. 成因分析}

A. 海温
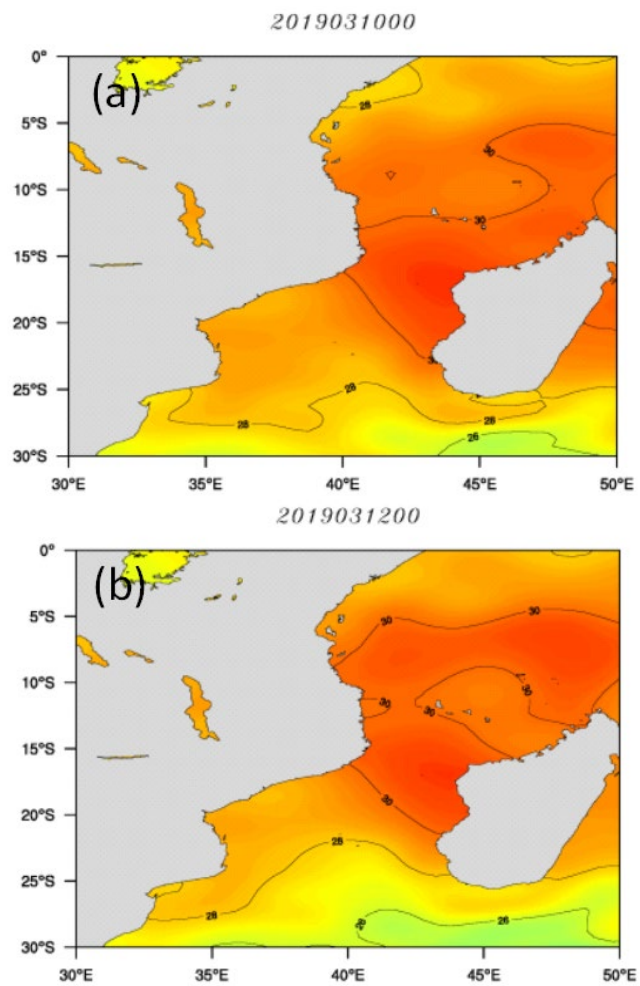


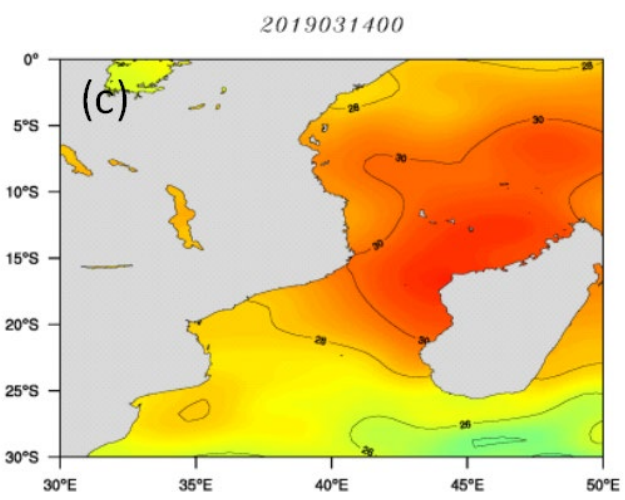

图 33 月 10 日(a)、12 日 (b)、14 日(c)日平均海温（单 位: ${ }^{\circ} \mathrm{C}$ )

暖的下垫面是热带气旋生成的必要条件之一。由于 海温的日变化相对较小，这里仅给出 3 月 10 日、12 日 和 14 日的日平均海温分布。从图中来看, 莫桑比克海 峡大部分海域海温高于 $30^{\circ} \mathrm{C}$, 南侧海域海温在 $28 \sim 30^{\circ} \mathrm{C}$ 之间，这种高海温的下垫面条件能够为热带气旋发展提 供能量。对应 “伊代” 发展的三个阶段, 其经过海域海 温均大于 $28^{\circ} \mathrm{C}$, 下垫面条件有利于其强度加强或维持。

\section{B. 环流形势}

$20190309+12$

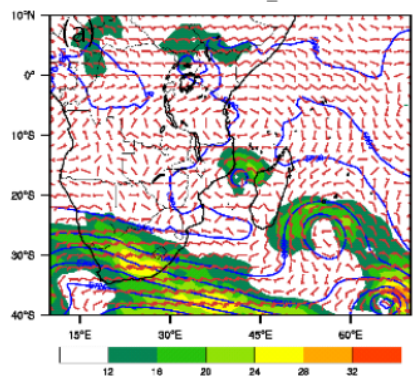

$20190311_{-} 12$

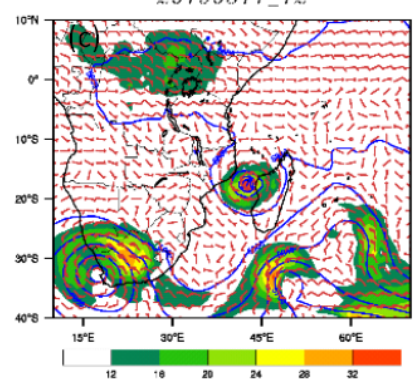

$20190313+12$

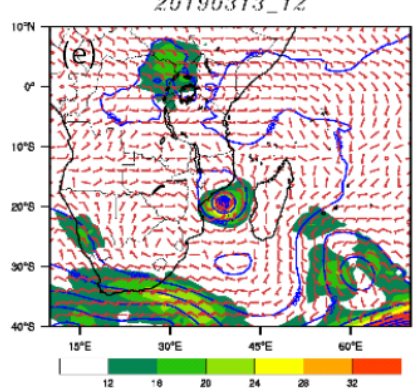

$20190310_{-} 12$
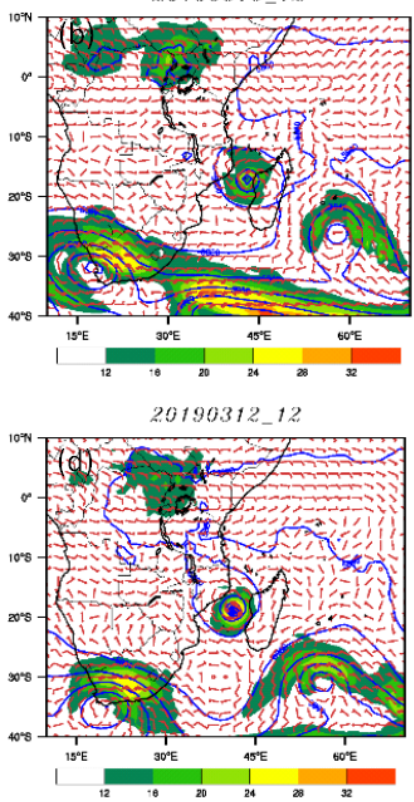

$20190311 \quad 12$

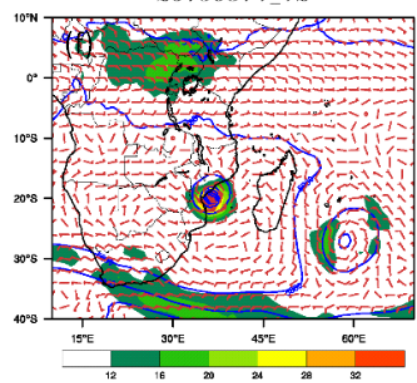

图 4 9-14 日(a-f)12 时 500hPa 位势高度 (等值线, 单位: 位势 米）、风速（阴影，单位： $\mathrm{m} / \mathrm{s}$ ）及风矢分布
从 $500 \mathrm{hPa}$ 环流形势来看, “伊代” 北侧为热带低压 区, 东北侧有一高压脊不断发展, 西南侧有一反气旋环 流不断发展。9-11 日, 由于南北两侧系统都较弱, 引导 气流较弱, 导致 “伊代” 移动缓慢, 在马达加斯加西海 岸附近停滞不前达一天以上。12 日以后, 其西南侧高压 发展, 向西的引导气流加强, 因此转向向西移动, 最终 登陆莫桑比克。

\section{C. 垂直风切变}

2019030918
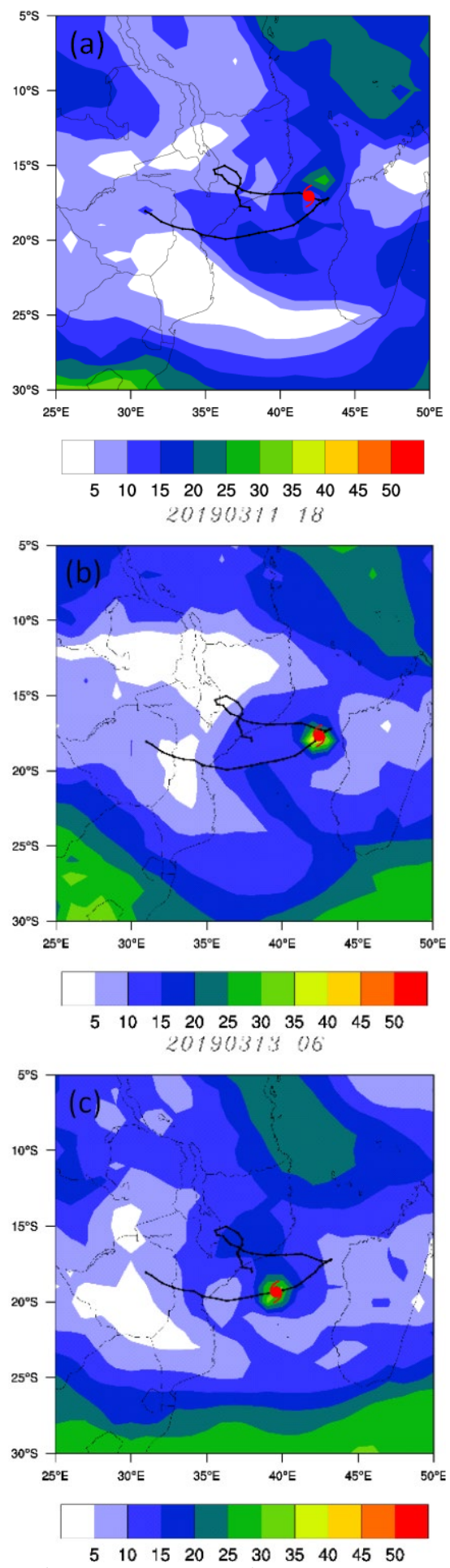

图 59 日 18 时 (a) 、11日18时 (b) 和 13 日 06 时 (c) 垂 直风切变分布 (单位: $\mathrm{m} / \mathrm{s}$ ) 
图 5 给出了 “伊代” 发展三个阶段起始时刻（9日 18 时、11 日 18 时和 13 日 06 时）环境风垂直切变的分 布。从图中可以看到, 莫桑比克海峡的垂直风切变约为 $10 \sim 15 \mathrm{~m} / \mathrm{s}$, 随着时间推移有减小趋势。整个发展过程 中, 环境风垂直切变维持在一个相对较小的水平, 既能 保证其暖心结构维持, 又能提供良好的通风环境, 有利 于其发展。

\section{D. 水汽条件}

图 6 给出了三个时次 $850 \mathrm{hPa}$ 水汽通量和风场的分 布。可以看到, “伊代” 发展过程中来自其它系统的水 汽输送非常弱, 几乎没有外部水汽来源, 仅在其减弱稳 定阶段（图 6b) 南侧东南气流能够提供微弱的水汽输 送。由此推测其水汽和能量主要来自高温高湿的海洋。

2010030978

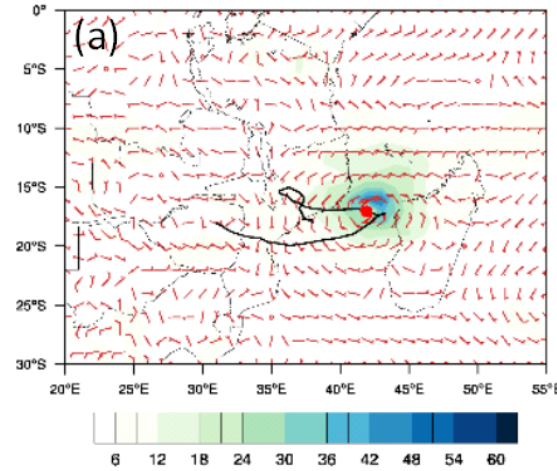

2019031110

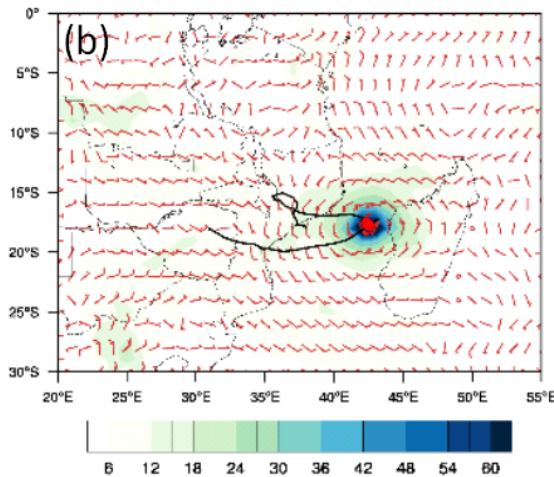

$201003 \times 306$

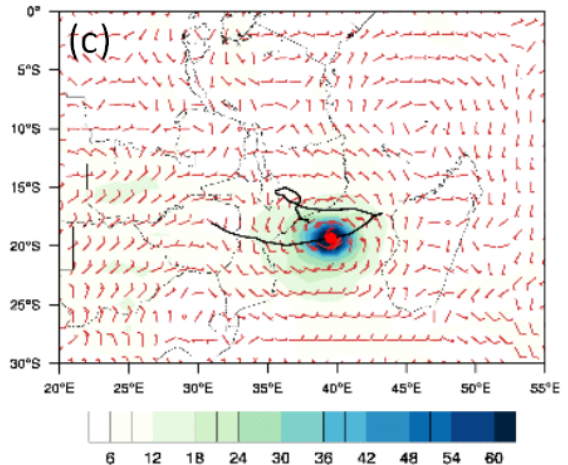

图 69 日 18 时 (a)、11日 18 时 (b) 和 13 日 06 时 (c) $850 \mathrm{hPa}$ 水汽通量 (单位: $\mathrm{g} \cdot \mathrm{cm}-1 \cdot \mathrm{hPa}-1 \cdot \mathrm{s}-1)$ 和风场

\section{E. 高层辐散条件}

图 7 为三个时次平均高层散度和 $200 \mathrm{hPa}$ 流场的分 布。从图中可以看到, “伊代” 高层的主要辐散区位于 北侧, 南侧相对较弱。整个发展过程中北侧的流出条件 都较好, 特别是第一个阶段即快速加强阶段开始前, 气 旋主体附近高层散度加大, 辐散区面积广, 有利于高层 抽吸作用加强对流产生, 促进对流爆发, 气旋强度增 大。
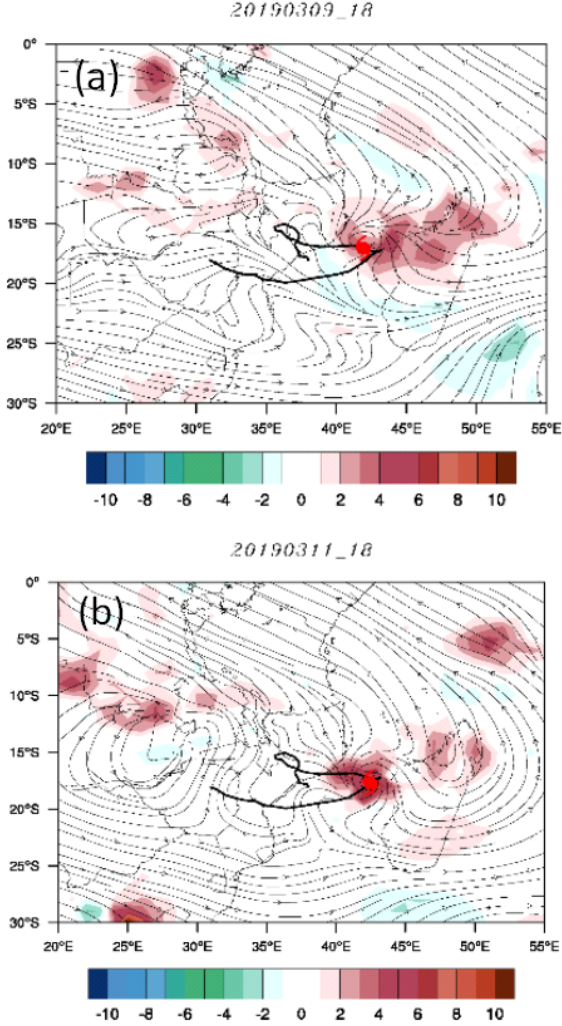

2019031300

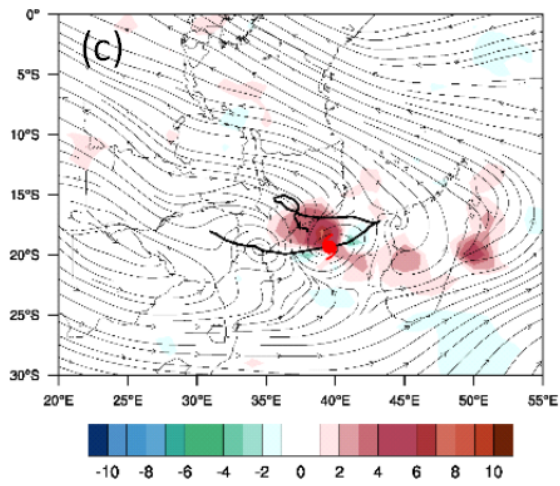

图 79 日 18 时（a）、11日 18 时 (b) 和 13 日 06 时 (c) 平均高层 (300-150hPa) 散度 (单位: $10-5 \mathrm{~s}-1$ ) 和 $200 \mathrm{hPa}$ 流 场分布

\section{V. 结论与讨论}

本文利用多种大气和海洋资料分析了西南印度洋强 热带气旋 “伊代（Idai）” 在莫桑比克海峡快速发展过 程中的强度变化、环流形势变化以及环境特征, 初步揭 示了其发展的成因, 主要结论有:

“伊代” 的发展主要经历了快速增强阶段, 减弱稳 定阶段和二次加强阶段, 在减弱稳定阶段实现眼墙重组 
后重新加强，最终发展为强热带气旋级。快速增强阶 段，其东北侧的高压脊及南侧高压的存在使得移动缓慢 甚至停滞不前, 后期南侧高压发展, 偏西气流引导其向 西移动。

“伊代”整个发展过程中经过的海域海温都大于 $28^{\circ} \mathrm{C}$, 较高的海温为其发展维持提供了能量, 同时, 对 水汽的诊断发现其发展过程中外部水汽输送较弱, 说明 海洋还为其发展提供水汽。整个发展过程中，环境风垂 直切变维持在一个相对较小的水平，既能保证其暖心结 构维持, 又能提供良好的通风环境, 高层辐散区主要位 于北侧, 随着气旋发展辐散区增大, 有利于高层抽吸促 进对流发展。

虽然对于热带气旋生成发展机理以及风险评估的研 究不断深入，全球热带气旋预报水平逐年提高，但是热 带气旋引起仍是致灾最严重的天气系统之一。基于情景 的定量化灾害损失评估和灾害分析还需加强，以便为决 策者和相关机构提供指导，最大程度地降低灾害风险。

\section{参考文献:}

[1] Ho, C. H., Kim, J. H., Jeong, J. H., Kim, H. S., \& Chen, D. . Variation of tropical cyclone activity in the South Indian Ocean: El NiñoSouthern Oscillation and Madden - Julian Oscillation effects. Journal of Geophysical Research: Atmospheres, 111(D22), 2006

[2] Mavume, A. F., Rydberg, L., Rouault, M., \& Lutjeharms, J. R. Climatology and landfall of tropical cyclones in the south-west Indian Ocean. Western Indian Ocean Journal of Marine Science, 8(1), 2009.

[3] Buckley, B. W., \& Leslie, L. M. Preliminary climatology and improved modelling of south Indian Ocean and Southern Ocean mid - latitude cyclones. International Journal of Climatology: A Journal of the Royal Meteorological Society, 24(10), 1211-1230, 2004.

[4] Shanko, D., \& Camberlin, P. The effects of the Southwest Indian Ocean tropical cyclones on Ethiopian drought. International Journal of Climatology: A Journal of the Royal Meteorological Society, 18(12), 1373-1388, 1998.

[5] Mawren, D., \& Reason, C. J. C. Variability of upper - ocean characteristics and tropical cyclones in the South West Indian Ocean. Journal of Geophysical Research: Oceans, 122(3), 2012-2028, 2017.

[6] South-West Indian ocean tropical Cyclone Experiment. A project to be submitted to CNRS-INSU \& Météo-France (LEFE/IDAO) Centre National d'Etudes Spatiales Agence National de la Recherche.2009.

[7] 隋广军, 唐丹玲等. 台风灾害评估与应急管理, 第三章 P44-46. 北京：科学出版社, 2015 . 